\title{
Study of the changes in the growth, protein, and bioactive profile of Chlorella emersonii KJ725233 in response to sodium and ammonium nitrate
}

\author{
Sneha Sunil Sawant, Varsha Kelkar-Mane* \\ Department of Biotechnology, University of Mumbai, Santacruz (E), Mumbai, India
}

\begin{tabular}{l}
\hline ARTICLE INFO \\
\hline Article history: \\
Received on: October 20, 2018 \\
Accepted on: February 06, 2019 \\
Available online: July 04, 2019 \\
\hline
\end{tabular}

Key words:

Chlorella emersonii KJ725233, cations, nitrate, antioxidant, vitamin E.

\begin{abstract}
Chlorella emersonii KJ725233 is a non-fastidious microalga isolated from the western regions of Maharashtra, India. The alterations in its chlorophyll, protein, and antioxidant content in response to cationic stress were studied. Chlorella emersonii KJ725233 (CEK) was subjected to $\mathrm{NaNO}_{3}$ and $\mathrm{NH}_{4}\left(\mathrm{NO}_{3}\right)^{2}$ at concentrations equivalent to $0.9 \mathrm{~g} / 1(1 \times)$ and $1.8 \mathrm{~g} / 1(2 \times)$ in the cultivation media. Qualitative alterations in the bioactives of the microalga were identified by gas chromatography-high-resolution mass spectrometry (GC-HRMS), while the protein, chlorophyll, and antioxidant manipulations were spectrophotometrically quantified. Doubling of the protein content was observed when CEK was grown in $1 \times \mathrm{NH}_{4}^{+}$, whereas in $2 \times \mathrm{NH}_{4}^{+}$, chlorosis was significant. $2 \times \mathrm{NH}_{4}^{+}$ also induced oxidative stress on CEK as evident from the $85.72 \% \pm 6.72 \%, 197.47 \% \pm 7.01 \%, 22.24 \% \pm 1.78 \%$, and $187.37 \% \pm 1.88 \%$ increase in antioxidant potential, ferric reducing capacity, radical scavenging potential, and total phenolic content, respectively, as compsared to CEK grown in $1 \times \mathrm{Na}^{+}$. These alterations as indicated from the GC-HRMS data correlate to the bioactive inductions/variations of/in Vitamin E, phytol, and its isomer in CEK grown in $2 \times \mathrm{NH}_{4}^{+}$. The study thus indicates that manipulations of nitrate salts in the media significantly induce, as well as alter the concentrations of commercially significant compounds like Vitamin E, phytol, etc.
\end{abstract}

\section{INTRODUCTION}

Cultural conditions such as nutrient composition, as well as their concentrations, temperature, light intensity, photoperiod, and $\mathrm{pH}$ are known to affect the growth and induce changes in the biochemical composition of microalgae [1]. This is mainly due to the stressed altered metabolic pathways leading to the induction of bioactives that eventually enable it in its survival and adaptation to the coarse growth environments [2]. Therefore, in order to explore the commercial potential of the microalga, there is a necessity to manipulate the growth conditions so as to alter the synthesis of biologically active microalgal compounds [3]. The amount of these bioactives is, however, largely species-specific and is not only reliant on growth conditions but also on the age of the culture [2].

\footnotetext{
*Corresponding Author

Varsha Kelkar-Mane, Department of Biotechnology, University of Mumbai, Santacruz (E),Mumbai, India.E-mail:drvkelkar@mu.ac.in
}

Nitrogen, the growth limiting factor, is incorporated in the algal culture media in the form of a variety of organic (amino acids and urea) or inorganic (nitrates, nitrites, and ammonium salts) nitrogen sources [4]. Alterations in the type and concentration of the nitrogen sources are known to affect the growth, as well as the lipid content of microalgae [3,5-11]. These nitrogen sources are usually first reduced to ammonium, which is directly taken up by facilitated diffusion and assimilated into amino acids $[5,12]$. It is also known to affect the protein synthesis by increasing the functional activity of the ribosomes and hence, the nutritional content [13]. Nitrate-N is the most widely used nitrogen source for microalgae since it is not known to evaporate on autoclaving of the media [14]. Also, unlike Ammonium-N, Nitrate-N is less likely to induce an acidic $\mathrm{pH}$ shift of the medium. Ammonium assimilation leads to a drop in $\mathrm{pH}$, thus reducing the growth rate, whereas a rise in $\mathrm{pH}$ can be observed in Nitrate-N growing culture with an increased growth rate [5]. Contrarily, sodium plays an important role in the nutrient transport system, especially in nitrate transport, as well as maintaining osmoregulation and photosynthesis [15]. The advantages and the role of nitrates along with sodium, 
therefore, make sodium nitrate the most preferred nitrate salt in the algal culture medium. The $\mathrm{pH}$ shifts induced may, in turn, alter the antioxidant status of the alga by stimulating the $\mathrm{pH}$-dependent reactive oxygen species (ROS) generating enzymes all of which mainly produce $\mathrm{H}_{2} \mathrm{O}_{2}[16]$.

Chlorella strains due to their cosmopolitan occurrence are naturally designed to counteract inconsistent environmental hostilities by synthesizing a variety of metabolites [4,17,18]. Chlorella emersonii KJ725233 - a novel, fast growing, non-fastidious microalga with inherently higher antioxidant content was isolated from the western regions of Maharashtra, India [19]. Though the effect of nitrate sources and its concentrations have been studied on the growth and lipid productivity of a few Chlorella species, its effect on the metabolic alterations and hence, antioxidant responses under such stressed conditions are still untapped. In order to exploit the potential of C. emersonii KJ725233 as a source of nutraceuticals and/or cosmeceuticals, the present study was designed to determine the effect of $\mathrm{Na}^{+}, \mathrm{NH}_{4}^{+}\left(\mathrm{NaNO}_{3}, \mathrm{NH}_{4} \mathrm{NO}_{3}\right)$ and their concentration on its growth (chlorophyll, carotenoids, and biomass), protein content, alterations in the bioactives, and hence, its antioxidant potential.

\section{MATERIALS AND METHODS}

\subsection{Microalgal Strain and Culturing}

Chlorella emersonii KJ725233 isolated from the western regions of Maharashtra, India [19], was cultured in BG-11 medium with a 12 hours photoperiod and 24 hours of aeration at $28^{\circ} \mathrm{C} \pm 2{ }^{\circ} \mathrm{C}$ till the logarithmic phase. After 15 days, this seed culture was inoculated into four different variants of BG-11 medium: (A) $1 \times$ $\mathrm{NaNO}_{3}(1.5 \mathrm{~g} / \mathrm{l}),(\mathrm{B}) 2 \times \mathrm{NaNO}_{3}(3.0 \mathrm{~g} / \mathrm{l}),(\mathrm{C}) 1 \times \mathrm{NH}_{4} \mathrm{NO}_{3}(1.4 \mathrm{~g} / \mathrm{l})$, and (D) $2 \times \mathrm{NH}_{4} \mathrm{NO}_{3}(2.8 \mathrm{~g} / \mathrm{l})$; such that the nitrate concentration in $1 \times \mathrm{NO}_{3}{ }^{-}$salt was $0.9 \mathrm{~g} / 1$, whereas in $2 \times$ it was $1.8 \mathrm{~g} / \mathrm{l}$. Since BG11 medium, in general, contains $1.5 \mathrm{~g} / 1$ of $\mathrm{NaNO}_{3}, 1 \times \mathrm{NaNO}_{3}$ was considered as a control. The alga was grown in the nitrate variants until the late stationary phase was reached.

\subsection{Measurement of Growth}

After every 5 days, $10 \mathrm{ml}$ of the culture was taken in a pre-weighed tube and centrifuged at 2,800 ref for 15 minutes. The biomass was weighed and extracted in methanol on a shaker at $60^{\circ} \mathrm{C}$ for 2 hours. These suspensions were centrifuged and the absorbance of the supernatant was read on a Thermo Fischer MultiScan Go at 665,652 , and $470 \mathrm{~nm}$. The chlorophyll, as well as carotenoid concentration in terms of $\mu \mathrm{g}$ chlorophyll/carotenoid content per gram fresh weight of chlorella emersonii KJ725233 (CEK) ( $\mu \mathrm{g} /$ $\mathrm{gfw})$ was determined by the following formulas [20,21]:

$$
\begin{aligned}
& \text { Chlorophyll a }_{(\mu \mathrm{g} / \mathrm{ml})}=16.72 * \text { Absorbance }_{(665)}-9.16 * \text { Absorbance }_{(652)} \\
& \text { Chlorophyll b }_{(\mu \mathrm{g} / \mathrm{ml})}=34.09 * \text { Absorbance }_{(652)}-15.28 * \text { Absorbance }_{(665)} \\
& \text { Carotenoids }_{(\mu \mathrm{g} / \mathrm{ml})}=\frac{\left(1,000 * \text { Absorbance }_{(470)}-1.63_{\text {Chlorophyll a } \left.-104.96_{\text {Chlorophyll b }}\right)}^{221}\right.}{221}
\end{aligned}
$$

After the late stationary phase was reached, the cultures were centrifuged at 2,800 rcf for 15 minutes and the biomass yield (g/l) was determined. The biomass was rinsed with distilled water and dried at $60^{\circ} \mathrm{C}$ for 48 hours. The dried biomass was then used to determine the protein content, antioxidant potential, phenolic content, and the metabolite alterations by gas chromatographyhigh-resolution mass spectrometry (GC-HRMS).

\subsection{Estimation of the Protein Content}

In order to determine the protein content, $0.2 \mathrm{~g}$ of dried biomass was extracted in $1 \mathrm{~N} \mathrm{NaOH}$. The extraction was carried out thrice and the supernatants were pooled together. The protein content was estimated by Bradford's method $[23,24]$.

\subsection{Preparation of Chlorella Emersonii KJ725233 Extracts}

The dried biomass of $C$. emersonii KJ725233 was suspended in methanol at a concentration of $0.1 \mathrm{~g} / \mathrm{ml}$. These suspensions were sonicated for 30 minutes in ice in a bath sonicator. The suspensions were centrifuged at 2,800 rcf for 15 minutes and the supernatants were transferred to a fresh plate. The extraction was carried out thrice and the supernatants were pooled together. One microliter of these extracts was taken up for the bioactives identification by GC-HRMS, whereas the remaining were allowed to dry at room temperature $\left(30^{\circ} \mathrm{C} \pm 2^{\circ} \mathrm{C}\right)$ and then reconstituted in absolute dimethyl sulfoxide. These dimethyl sulfoxide extracts were further used to determine the antioxidant, as well as phenolic content.

\subsection{Antioxidant Potential}

\subsubsection{Total antioxidant capacity}

The total antioxidant capacity (TAC) was determined by the phosphomolybdenum method described earlier [24]. Three hundred microliters of the TAC reagent $(0.6 \mathrm{mmol}$ sulphuric acid, $28 \mathrm{mmol}$ sodium sulphate, and $4 \mathrm{mmol}$ ammonium molybdate) was added to $30 \mu \mathrm{l}$ of the extracts and incubated at $95^{\circ} \mathrm{C}$ for 90 minutes. After incubation, the absorbance was measured at 695 $\mathrm{nm}$ in a Thermo Fishcer MultiScan Go. Ascorbic acid was used as a standard and antioxidant capacity was expressed as mg ascorbic acid equivalence per $\mathrm{g}$ dried biomass (mg/g AAE DW).

\subsubsection{Ferric reducing antioxidant potential}

The ferric reducing antioxidant potential (FRAP) was determined by the potassium ferricyanide method as reported [25]. To $50 \mu \mathrm{l}$ of the extracts, $125 \mu \mathrm{l}$ of $0.1 \%$ potassium ferricyanide was added and incubated at $50^{\circ} \mathrm{C}$ for 20 minutes. After incubation, $125 \mu \mathrm{l}$ of $10 \%$ trichloroacetic acid was added. One hundred microliters of these reaction mixtures were then transferred to fresh wells with an equal volume of distilled water. Finally, $20 \mu \mathrm{l}$ of $0.1 \%$ ferric chloride was added and the absorbance was immediately measured at $700 \mathrm{~nm}$ in a Thermo Fishcer MultiScan Go. Ascorbic acid was used as a standard and the FRAP was expressed as mg AAE per $g$ dried biomass (mg/g AAE DW).

\subsubsection{DPPH radical scavenging potential}

The radical scavenging potential was determined by 2,2 diphenyl- 1-picrylhydrazyl (DPPH) radical scavenging assay as previously described [26]. One hundred and fifty microliters of 0.2 $\mathrm{mM}$ methanolic DPPH was added to an equal volume of various concentrations of the extracts $(2-10 \mathrm{mg} / \mathrm{ml})$ and incubated in the 
dark at room temperature for 30 minutes. After incubation, the absorbance was measured at $517 \mathrm{~nm}$. Ascorbic acid was used as a standard. Percent inhibition was calculated by the following formula:

$$
\frac{\text { Absorbance }_{\text {(blank) }}-\text { Absorbance }_{\text {(test) }}}{\text { Absorbance }_{(\text {blank) }}} * 100=\% \text { inhibition }
$$

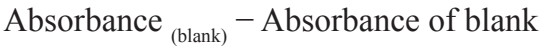

Absorbance $_{\text {(test) }}-$ Absorbance of test

A graph of extract concentration versus percent inhibition was plotted and inhibition concentration (IC) $)_{50}(\mathrm{mg} / \mathrm{ml})$ was determined.

\subsection{Total Phenolic Content}

The total phenolic content (TPC) was determined by the Folin's Ciocalteau method [27]. Twenty-five microliters of 1 N Folin's Ciocalteau reagent was added to $50 \mu \mathrm{l}$ of the extracts and incubated for 5 minutes at room temperature in the dark. After 5 minutes, $125 \mu \mathrm{l}$ of $20 \% \mathrm{Na}_{2} \mathrm{CO}_{3}$ was added and further incubated at room temperature in the dark. The absorbance was measured at 765 $\mathrm{nm}$ in a Thermo Fishcer MultiScan Go. Gallic acid was used as a standard and the TPC was expressed as mg gallic acid equivalence per $\mathrm{g}$ dried biomass (mg/g GAE DW).

\subsection{Identification of Bioactives by GC-HRMS}

GC-HRMS analysis of all the methanolic extracts was carried out using GC (Agilent Technologies, USA) equipped with Accutoff mass spectrometry (MS). Compounds were separated on HP-5 MS capillary column having $5 \%$ phenyl polysiloxane as stationaryphase, column length $30 \mathrm{~m}$, internal diameter $0.32 \mathrm{~mm}$, and film thickness $0.25 \mu \mathrm{m}$. One microliter of the methanolic extracts was injected in the split ratio of 10:1, the injector and transfer line temperatures were $250^{\circ} \mathrm{C}$ and $260^{\circ} \mathrm{C}$ while the ion source temperature was $200^{\circ} \mathrm{C}$. Oven temperature was programmed from $80^{\circ} \mathrm{C}$ to $280^{\circ} \mathrm{C}$ at $10^{\circ} \mathrm{C}$ minute $^{-1}$; flow rate of carrier gas helium was $1 \mathrm{ml}$ minute ${ }^{-1}$. Compounds were identified comparing their retention times and mass fragmentation patterns with the data of standards at the National Institute of Standards and Technology library [26].

\subsection{Statistical Analysis}

All experiments are performed in triplicates. Data are represented as mean \pm standard deviation. Data were analyzed using one-way analysis of variance, and a $p$-value less than 0.05 was considered to be statistically significant.

\section{RESULTS}

\subsection{Effect of Cations and its Concentration on Growth}

A time course analysis was performed to determine the alterations in the growth in terms of the chlorophyll and carotenoid content of $C$. emersonii KJ725233 in response to the nitrate variants. At 30 days of incubation, the highest chlorophyll content of 1,322.79 $\pm 7.2 \mu \mathrm{g} / \mathrm{g}$ fresh weight was observed in $C E K$ grown in $2 \times \mathrm{Na}^{+}$, whereas $C E K$ grown in $2 \times \mathrm{NH}_{4}^{+}$exhibited the lowest chlorophyll content of $663.69 \pm 9.85 \mu \mathrm{g} / \mathrm{g}$ fresh weight (Fig. 1). After 35 days of incubation, the highest biomass was obtained in $2 \times \mathrm{Na}^{+}$, whereas $2 \times \mathrm{NH}_{4}^{+}$severely affected the growth of the microalga (Table 1). A $12.81 \% \pm 0.13 \%$ increase in the biomass of C. emersonii KJ725233 in $2 \times \mathrm{Na}^{+}$thus can be attributed to the increased chlorophyll content. Chlorosis induced by $2 \times \mathrm{NH}_{4}^{+}$might have led to a $62.26 \% \pm 0.45 \%$ decrease in its biomass (Fig. 1, Table 1).

\subsection{Effect of Cations of Nitrate Salt on $\mathbf{p H}$}

The initial $\mathrm{pH}$ of all the four variants was equivalent; however, with the growth of $C$. emersonii KJ725233, the $\mathrm{pH}$ started becoming alkaline in case of $\mathrm{Na}^{+}$and acidic in case of $\mathrm{NH}_{4}^{+}$. In $\mathrm{Na}^{+}$, the $\mathrm{pH}$ increased from 7.2 to $9.2 \pm 0.1$, whereas in $\mathrm{NH}_{4}^{+}$, the $\mathrm{pH}$ decreased from 7.2 to $6.2 \pm 0.1$ after 35 days of incubation (Fig. 2).

\subsection{Effect of Cation of Nitrate Salt on Protein Content}

The highest protein content of $56.41 \pm 3.41 \mathrm{~g} \%$ signifying an increase of $102.99 \% \pm 6.66 \%$ was observed in CEK grown in the presence of $1 \times \mathrm{NH} 4+$ as compared to CEK grown in the presence of $1 \times \mathrm{Na}+$. Also, a $10 \%-12 \%$ increase in protein content was observed in CEK grown in the presence of $2 \times \mathrm{Na}+(30.83 \pm 1.37$ $\mathrm{g} \%)$ and $2 \times \mathrm{NH} 4+(31.58 \pm 0.38 \mathrm{~g} \%)$ (Table 1).

\subsection{Effect of Cation and its Concentration on Antioxidant Potential and Total Phenolic Content}

The highest antioxidant potential of $30.9 \pm 0.68 \mathrm{mg} / \mathrm{g}$ AAE was observed in $2 \times \mathrm{NH}_{4}^{+}$, whereas the lowest $8.55 \pm 0.96 \mathrm{mg} / \mathrm{g} \mathrm{AAE}$

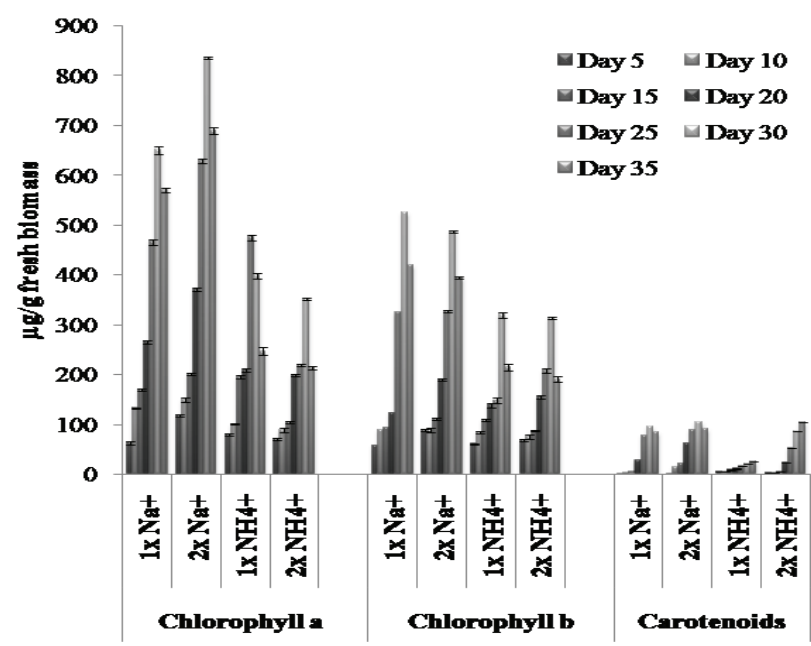

Figure 1: Effect of cations and their concentration on chlorophyll and carotenoid content of $C$. emersonii KJ725233 ( $p$ value $<0.05$ ).

Table 1: Effect of cations on the biomass and protein content of $C$. emersonii KJ725233.

\begin{tabular}{lcc} 
Cationic variants & Biomass $(\mathrm{g} / \mathbf{l})$ & Protein content $(\mathbf{g} \%)$ \\
$1 \times \mathrm{Na}^{+}$ & $11.794 \pm 0.025$ & $27.786 \pm 1.265$ \\
$2 \times \mathrm{Na}^{+}$ & $13.305 \pm 0.128$ & $30.833 \pm 1.376$ \\
$1 \times \mathrm{NH}_{4}^{+}$ & $8.599 \pm 0.024$ & $56.416 \pm 3.412$ \\
$2 \times \mathrm{NH}_{4}^{+}$ & $4.451 \pm 0.117$ & $31.25 \pm 0.75$ \\
\hline
\end{tabular}

Values are expressed as mean \pm SD. $p$ value of less than 0.05 was considered to be significant. 
was observed in $1 \times \mathrm{NH}_{4}^{+}$(Table 2). Significant alteration of $85.72 \% \pm 6.72 \%, 197.47 \% \pm 7.01 \%$, and $187.37 \% \pm 1.88 \%$ in total antioxidant potential, FRAP, and TPC was observed in $2 \times$ $\mathrm{NH}_{4}^{+}$as compared to the control $1 \times \mathrm{Na}^{+}$.

The highest $\mathrm{IC}_{50} 7.58 \pm 0.18 \mathrm{mg} / \mathrm{ml}$ was observed in $2 \times \mathrm{Na}^{+}$, whereas the lowest $4.19 \pm 0.07 \mathrm{mg} / \mathrm{ml}$ was observed for $2 \times \mathrm{NH}_{4}^{+}$ (Fig. 3). A significant increase of $22.24 \% \pm 1.78 \%$ was seen in the $\mathrm{IC}_{50}$ of $2 \times \mathrm{NH}_{4}^{+}$as compared to that of the control $1 \times \mathrm{Na}^{+}$.

\subsection{Metabolite Profiles of Chlorella emersonii KJ725233 by GC-HRMS Analysis}

In order to confirm that the quantitative alterations observed in the antioxidant potential could be due to a corresponding occurrence of any such modifications in the antioxidant metabolites, the methanolic extracts of $1 \times \mathrm{Na}^{+}$and $2 \times \mathrm{NH}_{4}^{+}$were subjected to GCHRMS analysis. GC-HRMS analysis revealed qualitative, as well as quantitative alterations in the metabolites in response to the two cations (Table 3 ).

Phytol, its isomer 3,7,11,15-Tetramethyl-2-hexadecen-1-ol and 1Docosene were found at higher concentrations of $17.79 \%, 17.94 \%$, and $9.51 \%$, respectively, in $2 \times \mathrm{NH}_{4}^{+}$. Similarly, alterations were also observed in the induction of hydrocarbons, as well as the fatty acids in both $\mathrm{Na}^{+}$as well as $\mathrm{NH}_{4}^{+}$. The sterols induced in the presence of sodium were not observed in $2 \times \mathrm{NH}_{4}^{+}$; however, the lipid-soluble antioxidant Vitamin $\mathrm{E}$ marked its existence in the same.

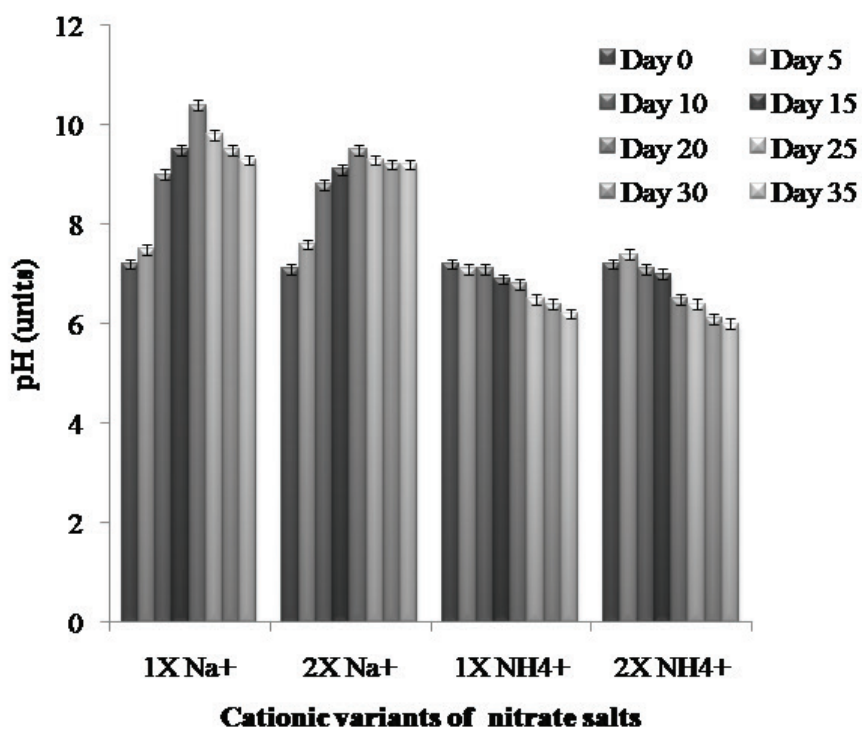

Figure 2: Effect of cations and their concentrations on $\mathrm{pH}$ of the culture media $(p$ value $<0.05)$

Table 2: Effect of cations on the TAC, FRAP, and the TPC.

\begin{tabular}{lcccc} 
& $\mathbf{1} \times \mathbf{N a}^{+}$ & $\mathbf{2} \times \mathbf{N a}^{+}$ & $\mathbf{1} \times \mathbf{N H}_{4}^{+}$ & $\mathbf{2} \times \mathbf{N H}_{4}^{+}$ \\
TAC $(\mathrm{mg} / \mathrm{g}$ AAE$)$ & $16.65 \pm 0.45$ & $11.2 \pm 0.086$ & $8.55 \pm 0.94$ & $30.9 \pm 0.69$ \\
FRAP $(\mathrm{mg} / \mathrm{g}$ AAE $)$ & $6.25 \pm 0.45$ & $4.35 \pm 0.18$ & $2.82 \pm 0.23$ & $18.57 \pm 0.80$ \\
TPC $(\mathrm{mg} / \mathrm{g}$ GAE$)$ & $1.77 \pm 0.06$ & $1.79 \pm 0.02$ & $1.29 \pm 0.03$ & $5.08 \pm 0.17$ \\
\hline Values are represented as mean \pm SD. $p$ values less than 0.05 were considered to be significant.
\end{tabular}

\section{DISCUSSION}

In order to determine the cationic effect of nitrate salts on the biomass as well as chlorophyll, carotenoid content of CEK, a time course analysis was performed. The study revealed though nitrate concentrations were kept constant, $\mathrm{Na}+$ at a higher concentration stimulated growth in terms of both biomass productivity, as well as chlorophyll content, whereas $\mathrm{NH} 4+$ at a higher concentration repressed growth as evident by chlorosis and hence an increase in carotenoid content. Nitrogen manipulations are known to distress photosynthesis by reducing the proficiency of energy assemblage owing to chlorophyll loss and hence result in an increase in the non-photochemically active carotenoids [28].

Since the uptake of ammonium is energy efficient, it appears to be a favorable nitrogen source; however, factors like light intensity, presence of organic carbon, and transport of other molecules result in alternative algal nitrogen preferences [14]. Also, ammonium at higher concentrations decreases the $\mathrm{pH}$ of the medium by releasing $\mathrm{H}^{+}$cells, thus becoming inhibitory to cell growth, as well as causing cell lysis [5]. Similar results are earlier reported wherein they reported that the maximal biomass productivity of Scenedusmus bijugatus was observed in the presence of sodium nitrate over ammonium nitrate [29]. In the culture medium, ammonium nitrate splits up into ammonium ions (charged ionic ammonia species) and nitrate. These charged hydrated ammonium ions are known to be transported into the cell via specific channels. Ammonium, however, acts as a weak acid and further splits into the unionized uncharged ammonia species and a proton [30]. An increase in the protein content of Helianthus annus L. var Mammoth Russian in the presence of both ammonium and nitrate has been reported [31]. Also, a seven-fold increase in ribosome number of Soybean mixotrophic callus was observed in the presence of ammonium at 10-20 $\mathrm{mM}$ [13]. In the present study, $17.653 \mathrm{mM} \mathrm{NH}_{4}^{+}$, as well as the presence of nitrate in $1 \times \mathrm{NH}_{4} \mathrm{NO}_{3}$ could, therefore, have led to a doubling in the protein content. $7.6 \mathrm{mM}$ is the average optimum ammonium concentration for the Chlorophycean algae (Chlorella vulgaris, Chlorella protothecoides, Chlorella sp.); however,

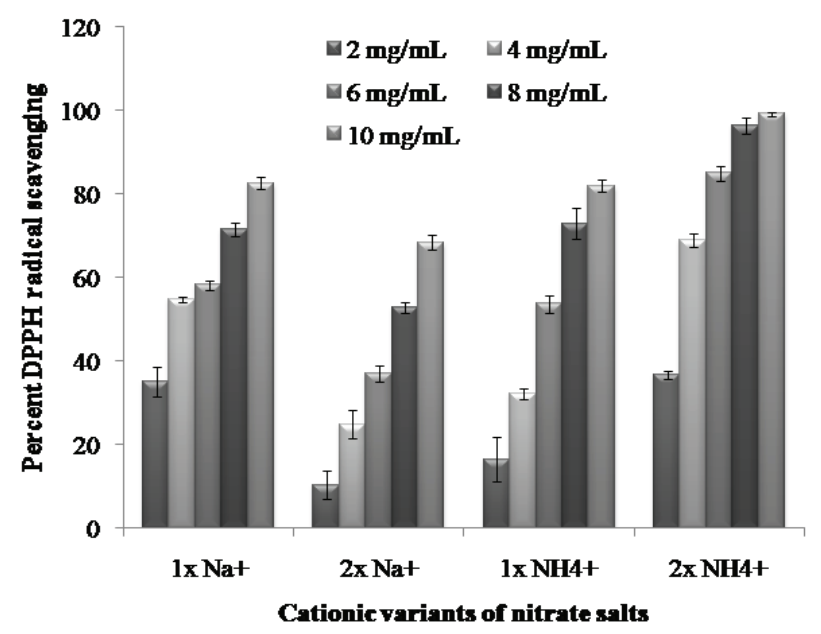

Figure 3: Effect of cations and their concentration on the radical scavenging activity of $C$. emersonii KJ725233 ( $p$ value $<0.05$ ). 
Table 3: Effect of nitrate stress on compounds synthesized by C. emersonii KJ725233 as identified by GC-HRMS.

\begin{tabular}{|c|c|c|c|c|}
\hline \multirow[t]{2}{*}{ RT } & \multicolumn{2}{|l|}{$1 \times \mathrm{NaNO}_{3}$} & \multicolumn{2}{|l|}{$2 \times \mathrm{NH}_{4} \mathrm{NO}_{3}$} \\
\hline & Compound & Area (\%) & Compound & Area (\%) \\
\hline 17 & Heptadecane & 4.5 & - & - \\
\hline 18.89 & 3,7,11,15-Tetramethyl-2-hexadecen-1-ol & 0.89 & 3,7,11,15-Tetramethyl-2-hexadecen-1-ol & 15.92 \\
\hline 20.57 & 9,12-Octadecadienoic acid & 3.577 & - & - \\
\hline 20.70 & cis, cis $-7,10$-Hexadecadienal & 9.1 & - & - \\
\hline 21.05 & $\mathrm{n}$-Hexadecanoic acid & 13.1 & $\mathrm{n}$-Hexadecanoic acid & 6.72 \\
\hline 21.55 & Phytol & 0.34 & - & - \\
\hline 23.46 & 9,12- Octadecadienoic acid methyl ester & 0.88 & - & - \\
\hline 23.57 & 9-Octadecanoic acid methyl ester & 1.04 & - & - \\
\hline 23.87 & - & - & Phytol & 17.79 \\
\hline 24.33 & 9,12- Octadecadienoic acid & 20.3 & 9,12 - Octadecadienoicacid & 23.45 \\
\hline 25.42 & - & - & 3,7,11,15-Tetramethyl-2-hexadecen-1-ol & 2.02 \\
\hline 28.9 & 1-Docosene & 4.77 & 1-Docosene & 9.51 \\
\hline 29.68 & Ergosterol & 4.54 & - & - \\
\hline 31.05 & Stigmasterol & 20.95 & 13,14-Epoxytetradec-11-en-1-ol acetate & 8.57 \\
\hline 38.95 & - & - & Vitamin E & 4.89 \\
\hline
\end{tabular}

$\mathrm{RT}=$ retention time in mins; Area \% = Percentage area of the chromatogram.

they are able to tolerate ammonium at a concentration as high as $39 \mathrm{mM}[32]$.

Unlike ammonium, uncharged ammonia species is highly permeable to the biological membrane and, therefore, penetrates into the cell through simple diffusion, thus causing swelling eventually leading to osmotic lysis of the cells [30]. Free ammonia toxicity not only just leads to lower cell densities but also induces oxidative stress leading to a decline in chlorophyll content and hence an overproduction of ROS. Free ammonia is known to induce light-dependent photodamage of photosystem II, thereby affecting the photosynthetic machinery [33]. Due to the excessive photosynthetic light, the production of ROS is accelerated at both the photosystems I and II. To counteract this oxidative stress, chloroplasts promote ROS scavenging through alterations in the antioxidant compounds (water soluble such as ascorbate, phenols; lipid soluble such as $\alpha$-tocopherol), as well as antioxidant enzymes (superoxide dismutase, ascorbate peroxidase, and catalase) [34].

Chlorosis induced by $2 \times \mathrm{NH}_{4}^{+}$led to a corresponding increase in the chlorophyll degradation product phytol along with its isomer 3,7,11,15-Tetramethyl-2-hexadecen-1-ol. Phytol is reported as an antioxidant, anti-nociceptive, anti-inflammatory, antimycobacterial, and anti-microbial whereas its isomer is a known antioxidant, as well as anti-microbial [35-39]. Phytol when phosphorylated yields phytyl-phosphate and phytyl-diphoshphate, which subsequently would feed into the tocopherol biosynthesis pathway [40]. The induction of this potent lipophilic antioxidant Vitamin E might, therefore, be attributed to the higher availability of phytol and its isomer in $2 \times \mathrm{NH}_{4}^{+}$.

Apart from Vitamin E, 9,12-Octadecadienoic acid methyl ester was also identified in $2 \times \mathrm{NH}_{4}^{+}$at an equivalent concentration of that of the essential fatty acid 9,12-Octadecadienoic acid in the control. 9,12-Octadecadienoic acid methyl ester is reported as an anticancer compound [41]. The unusual sterols of Chlorella, i.e., Ergosterol and Stigmasterol induced in $\mathrm{Na}^{+}$but not in $\mathrm{NH}_{4}^{+}$are reported hypocholesterolemic agents [42,43]. Higher concentrations of $\mathrm{NH}_{4}^{+}$are known to hinder sterol synthesis and hence could have accounted for their disappearance in $2 \times \mathrm{NH}_{4}^{+}$ $[44,45]$. Sterols play a significant role in maintaining the algal cellular membrane fluidity and hence permeability. Moreover, they serve as phytohormonal precursors and are involved in signal transduction in these organisms [46]. The hindrance in sterol synthesis could possibly be a defense mechanism of the alga to combat the $\mathrm{NH}_{4}^{+}$induced stress.

The antioxidant potential due to non-enzymatic antioxidants such as ascorbic acid, phenols, $\alpha$-tocopherols, carotenoids, and reduced glutathione was measured by the phosphomolybdenum method, whereas that of hydrophilic antioxidants such as phenols was evaluated by the FRAP method $[47,48]$. Therefore, the quantitative alterations observed in the TAC and the FRAP could be attributed to a corresponding increase in the synthesis and/or induction of the antioxidant compounds in $2 \times \mathrm{NH}_{4}^{+}$. The increase in radical scavenging activity due to the lipophilic antioxidants as evaluated by DPPH might be due to the induction of the lipidsoluble antioxidant Vitamin $\mathrm{E}$ in $2 \times \mathrm{NH}_{4}^{+}$. In addition, phenols are considered to be exhibiting strong antioxidant potential due to their ability to inactivate free radicals, as well as prevent decomposition of hydrogen peroxides into free radicals [35]. Thus, the boosting of these potent antioxidants could attribute to the increased antioxidant potential of $2 \times \mathrm{NH}_{4}^{+}$.

The non-fastidious, robustly growing C. emersonii KJ725233 when subjected to varying nitrate conditions exhibited an increased growth in media with $2 \times \mathrm{Na}^{+}$. Its growth was, however, repressed in the media with $1 \times \mathrm{NH}_{4}^{+}$and chlorosis set in $2 \times \mathrm{NH}_{4}^{+}$. However, the protein content doubled when grown in media containing $1 \times$ $\mathrm{NH}_{4}^{+}$as compared to $\mathrm{Na}^{+}$. Although at $2 \times \mathrm{NH}_{4}^{+}$, the biomass was severely compromised due to chlorosis, an overproduction of ROS could have led to a doubling of its antioxidant content because 
of the induction of the potent lipophilic antioxidant-Vitamin E. Although the responses may be species-specific, an appropriate cationic salt of nitrate should be considered for mass culturing of the alga depending upon the final nutraceutical and cosmeceutical formulations.

\section{CONFLICT OF INTEREST}

The authors declare no conflict of interest.

\section{FUNDING}

The authors would like to acknowledge the support from the University of Mumbai to carry the above study at the Department of Biotechnology, University of Mumbai.

\section{ETHICS STATEMENT}

We give our consent to participate under the 'Ethics, consent, and permissions' heading as applicable.

\section{REFERENCES}

1. Pancha I, Chokshi K, George B, Ghosh T, Paliwal C, Maurya R, et al. Nitrogen stress triggered biochemical and morphological changes in the microalgae Scenedesmus sp. CCNM 1077. Bioresour Technol 2014;156:146-54.

2. Gacheva GV, Gigova LG. Biological activity of microalgae can be enhanced by manipulating the cultivation temperature and irradiance. Cent Eur J Biol 2014;9:1168-81.

3. Campos H, Boeing WJ, Dungan BN, Schaub T. Cultivating the marine microalga Nannochloropsis salina under various nitrogen sources: effect on biovolume yields, lipid content and composition, and invasive organisms. Biomass Bioenerg 2014;66:301-7.

4. Wu S, Zhou J, Xin Y, Xue S. Nutritional stress effects under different nitrogen sources on the genes in microalga Isochrysis zhangjiangensis and the assistance of Altermonas macleodii in releasing the stress of amino acid deficiency. J Phycol 2015;51:885-95.

5. Kim G, Mujtaba G, Lee K. Effects of nitrogen sources on cell growth and biochemical composition of marine chlorophyte Tetraselmis sp. for lipid production. Algae 2016;31:257-66.

6. Li T, Xu J, Gao B, Xiang W, Li A, Zhang C. Morphology, growth, biochemical composition and photosynthetic performance of Chlorella vulgaris (Trebouxiophyceae) under low and high nitrogen supplies. Algal Res 2016;16:481-91.

7. Li XY, Zhao FJ, Yu DD. Effect of nitrogen limitation on cell growth, lipid accumulation and gene expression in Chlorella sorokiniana. Braz Arch Biol Technol 2015;58:462-67.

8. Ren HY, Liu BF, Ma C, Zhao L, Ren NQ. A new lipid-rich microalga Scenedesmussp. strain R-16 isolated using Nile red staining: effects of carbon and nitrogen sources and initial $\mathrm{pH}$ on the biomass and lipid production. Biotechnol Biofuels 2013;6:143.

9. Ngangkham M, Ratha SK, Prasanna R, Saxena AK, Dhar DW, Sarika C, et al. Biochemical modulation of growth, lipid quality and productivity in mixotrophic cultures of Chlorella sorokiniana. SpringerPlus 2012;1:33.

10. Ordog V, Stirk WA, Balint P, Staden JV, Lovasz C. Changes in lipid, protein and pigment concentrations in nitrogen-stressed Chlorella minutissima cultures. J Appl Phycol 2012;24:907-14.

11. Nigam S, Rai MP, Sharma R. Effect of nitrogen on growth and lipid content of Chlorella pyrenoidosa. Am J Biochem Biotechnol 2011;7:124-9.

12. Pritchard DW, Hurd CL, Beardall J, Hepburn CD. Restricted use of nitrate and a strong preference for ammonium reflects the nitrogen ecophysiology of a light limited red alga. J Phycol 2015;51:277-87.
13. Smolov AP, Semenova GA. Effects of ammonium concentration on protein and chlorophyll contents and the number of ribosomes in the cells of soyabean mixotrophic callus. Russ J Plant Physiol 2008;55:359-64.

14. Podevin M, Francisci DD, Holdt SL, Angelidaki I. Effects of nitrogen source and acclimatization on specific growth rates of microalgae determined by a high throughput in vivo microplate autofluorescence method. J Appl Phycol 2015;27:1415-23.

15. Rinanti A. Biotechnology carbon capture and storage by microalgae to enhance $\mathrm{CO}_{2}$ removal efficiency in closed system photobioreactor. In: Thajuddin N, Dhanasekaran D (eds.). Algae organisms for imminent biotechnology, InTech, Croatia, pp 133-56, 2017.

16. Das K, Roychoudhury A. Reactive oxygen species (ROS) and response of antioxidants as ROS-scavengers during environmental stress in plants. Front Environ Sci 2014;2. doi:10.3389/fenvs.2014.00053

17. Najdenski HM, Gigova LG, Iliev II, Pilarski PS, Lukavsky J, Tsvetkova IV, et al. Antibacterial and antifungal activities of selected microalgae and cyanobacteria. Int J Food Sci Technol 2013;48: $1533-40$.

18. $\mathrm{Xu} \mathrm{J,} \mathrm{Hu} \mathrm{H.} \mathrm{Screening} \mathrm{high} \mathrm{oleaginous} \mathrm{Chlorella} \mathrm{strains} \mathrm{from} \mathrm{different}$ climate zones. Bioresour Technol 2013;144:637-43.

19. Sawant SS, Joshi AA, Bhagwat A, Mane VK. Tapping the antioxidant potential of a novel isolate-Chlorella emersonii. World J Pharm Res 2014;3:726-39.

20. Henriques M, Silva A, Rocha J. Extraction and quantification of pigments from a marine microalga : a simple and reproducible method. In: Mendez-Vilas A (ed.). Communicating current research and educational topics and trends in applied microbiology. Formatex, Spain, pp 586-93, 2007.

21. Lichtenthaler HK, Buschmann C. Chlorophyll and carotenoids: measurement and characterization by UV-VIS Spectroscopy. In: Wrolstad R, Acree TE, Haejung A, Decker EA, Penner MH, Reid DS, et al., (eds.). Current protocols in food analytical chemistry. John Wiley \& sons Inc., New York, NY, pp F4.3.1-8, 2001.

22. Bradford MM. A rapid and sensitive method for the quantitation of microgram quantities of protein utilising the principle of protein-dye binding. Anal Biochem 1976;72:248-54.

23. Prieto P, Pineda M, Aguilar M. Spectrophotometric quantitation of antioxidant capacity through the formation of phosphomolybdenum complex: specific application to the determination of vitamin E. Anal Biochem 1999;269:337-41.

24. Hemalatha A, Girija K, Parthiban C, Saranya C, Anantharaman P. Antioxidant properties and total phenolic content of a marine diatom Navicula clavata and green microalgae Chlorella marina and Dunaliella salina. Adv Appl Sci Res 2013;4:151-7.

25. Bendaoud H, Bouajila J, Rhouma A, Romdhane M. GC/MS analysis and antimicrobial and antioxidant activities of essential oil of Eucalyptus radiata. J Sci Food Agri 2009;89:1292-7.

26. Wu LC, Ho JAA, Shieh MC, Lu IW. Antioxidant and antiproliferative activities of Spirulina and Chlorella water extracts. J Agri Food Chem 2005;53:4207-12.

27. Benavente-Valdes JR, Aguilar C, Contreras-Esquivel JC, MendezZavala A, Montanez J. Strategies to enhance the production of photosynthetic pigments and lipids in chlorophyceae species. Biotechnol Rep 2016;10:117-25.

28. Arumugam M, Agarwal A, Arya MC, Ahmed Z. Influence of nitrogen sources on biomass productivity of microalgae Scenedesmus bijugatus. Bioresour Technol 2013;131:246-9.

29. Nokkaew A, Triampo W, Amornsamankul S, Pimpunchat B, Modchang C, Triampo D. Ammonia uptake by unicellular green microalgae: mathematical modelling and parameter optimization. Southeast Asian J Sci 2013;2:41-51.

30. Weismann GS. Effect of ammonium and nitrate nutrition on protein level and exudates composition. Plant Physiol 1964;39:947-52.

31. Collos Y, Harrison PJ. Acclimation and toxicity of high ammonium concentrations to unicellular algae. Marine Poll Bull 2014;80:8-23. 
32. Markou G, Vandamme D, Muylaert K. Microalgal and cyanobacterial cultivation: the supply of nutrients. Water Res 2014;65:186-202.

33. Takahashi S, Bagder MR. Photoprotection in plants: a new light on photosystem II damage. Trends Plant Sci 2011;16:53-60.

34. Suffo A, Ashish R, Pamo TE, Kuiate JR. Effect of processing methods on chemical composition and antioxidant activities of two Amaranthus sp. harvested in west region of cameroons. J Nutr Food Sci 2016; 477.

35. Olofsson P, Hultqvist M, Hellgren LI, Holmdahl R. Phytol: a chlorophyll component with anti-inflammatory and metabolic properties. In: Jacob $\mathrm{C}$, Kirsch $\mathrm{G}$, Slusarenko AJ, Winyard PG, Burkholz T (eds.). Recent advances in redox active plant and microbial products. Springer, Netherlands, pp 345-59, 2014.

36. Pejin B, Savic A, Sokovic M, Glamoclija J, Ciric A, Nikolic M, et al. Further in vitro evaluation of antiradical and antimicrobial activities of phytol. Nat Prod Res 2014;28:372-6.

37. Santos CCMP, Salvadori MS, Mota VG, Costa LM, De Almeida AAC, De Oliveira GAL, et al. Antinociceptive and antioxidant activities of Phytol in vivo and in vitro models. Neurosci J 2013;2013:1-9.

38. Rajab MS, Cantrell CL, Franzblau SG, Fischer NH. Antimycobacterial activity of (E)-phytol and derivatives: a preliminary structure- activity study. Planta Med 1998;64:2-4.

39. Vom DK, Holzl G, Plohmann C, Eisenhut M, Abraham M, Weber AP, et al. Remobilization of phytol from chlorophyll degradation is essential for tocopherol synthesis and growth of Arabidopsis. Plant Cell 2015;27:2846-59.

40. Abubakar MN, Majinda RRT. GCMS analysis and preliminary antimicrobial activity of Albizia adianthifolia (Schumach) and Pterocarpus angolensis. Medicine 2016;3:1-9.

41. Moselhy SS, Kamal IH, Kumosani TA, Huwait EA. Possible inhibition of hydroxy methyl glutaryl CoA reductase activity by nicotinic acid and ergosterol: as targeting for hypocholesterolemic action. Afr Health Sci 2016;16:319-24.

42. Rahman MA, Abdoolah N, Aminudin N. Inhibitory effect on invitro LDL oxidation and HMG-CoA reductase activity of the liquid liquid partitioned fractions of Hericium erinaceus (Bull.) Persoon (Lion's Mane mushroom). Biomed Res Int 2014;2014:1-9.

43. Wallander $\mathrm{H}$, Nylund J. Effects of excess nitrogen on carbohydrate concentration and mycorrhizal development of Pinus sylvestris L. seedlings. New Phytol 1991;119:405-11. doi:10.1111/j.1469-8137.1991.tb00040.x
44. Novotny C, Beran K, Behalova B, Dolezalova L, Zajicek J. Effect of ammonium ions on delta 5,7-sterol synthesis in Saccharomyces cerevisiae. Folia Microbiol 1987;32:206-10.

45. Luo X, Su P, Zhang W. Advances in microalgae-derived phytosterols for functional food and pharmaceutical applications. Mar Drugs 2015;13:4231-54.

46. Pal RS, Kumar AR, Agrawal PK, Bhatt JC. Antioxidant capacity and related phytochemical analysis of methanolic extract of two wild edible fruits from North western Indian Himalaya. Int J Pharm Biosci 2013;4:113-23.

47. Apak R, Guclu K, Demirata B, Ozyurek M, Celik SE, Bektasoglu B, et al. Comparative evaluation of various total antioxidant capacity assays applied to phenolic compounds with the CUPRAC assay. Molecules 2007;12:1496-547.

\section{How to cite this article:}

Sawant SS, Kelkar-Mane V. Study of the changes in the growth, protein, and bioactive profile of Chlorella emersonii KJ725233 in response to sodium and ammonium nitrate. J Appl Biol Biotech 2019;7(04):19-25. DOI: 10.7324/ JABB.2019.70404 